Puspitasari, Kholdani, Arminarahmah - Sistem Penunjang Keputusan Pemilihan Atlet Panjat Tebing Menggunakan Metode Simple Additive Weighting

\title{
SISTEM PENUNJANG KEPUTUSAN PEMILIHAN ATLET PANJAT TEBING MENGGUNAKAN METODE SIMPLE ADDITIVE WEIGHTING
}

\author{
Desy Ika Puspitasari ${ }^{1}$, Al Fath Riza Kholdani ${ }^{2}$, Nur Arminarahmah ${ }^{3}$ \\ Fakultas Teknologi Informasi, UNISKA MAB Banjarmasin \\ Email : smile4desyka@gmail.com ${ }^{1}$, kholdanialfath@gmail.com ${ }^{2}$, zahifah@gmail.com ${ }^{3}$
}

\begin{abstract}
ABSTRAK
Sebagaimana diketahui, olahraga panjat tebing termasuk jenis kategori olahraga populer dikalangan remaja sekarang ini, terbukti dengan seringnya dilaksanakan kejuaraan panjat tebing baik skala nasional maupun interrnasional. Sebelum mengikuti sebuah ajang kompetisi, atlet akan menjalani program latihan yang dibuat oleh Pelatih dan koordinator Pembinaan dan Prestasi (Binpres) Federasi Panjat Tebing Indonesia (FPTI) untuk memaksimalkan kemampuan atlet sebelum mengikuti kejuaraan.Berdasarkan masalah tersebut, maka diperlukan sistem penunjang keputusan yang dapat membantu tim FPTI kab. Tapin dalam memilih kemampuan fisik dan mental atlet agar mencapai target juara yang diharapkan. Guna menentukan nilai bobot untuk kriteria penilaian sampai dengan terpilih alternatif terbaik, metode Simple Additive Weighting (SAW) digunakan dalam sistem ini dengan memberikan pertimbangan pemberian bobot atas empat kategori yaitu daya tahan, teknik, fisik, dan strategi. Hasil penelitian menunjukkan perbandingan antara proses manual (pretest) dan menggunakan aplikasi (postest) untuk data awal dengan total data sebanyak 30 data terdapat 0 data yang tidak sesuai (0\%) dan 30 data yang sesuai (100\%). Hal ini menunjukkan dengan adanya aplikasi penentuan atlet panjat pelatih tidak lagi membuat data manual dan dapat memilih kategori penilaian ketahanan, fisik, teknik dan taktik yang mana yang ingin di prioritaskan menggunakan faktor bobot aplikasi.
\end{abstract}

Kata kunci : atlet, panjat tebing, SAW, sistem penunjang keputusan

\begin{abstract}
As known, rock climbing sports including the type of popular sports categories among teenagers today, as evidenced by the frequent rock climbing championship performed both national and international scale. Before join competition, athletes will undergo a training program created by Coach and Coordinator of Development and Achievement (Binpres) Federasi Panjat Tebing Indonesia (FPTI) to maximize the ability of athletes before the championship. Based on that problem, it is needed a decision support system that can help the FPTI Tapin team, in choosing the physical and mental ability of the athlete to reach the expected champion target. In order to determine the weighting value for the assessment criteria until the chosen best alternative, Simple Additive Weighting (SAW) method is used in this system by giving consideration of the weighting of four categories namely endurance, technique, physical, and strategy. The results of comparison show between manual process (pretest) and using application (postest) for initial data with total data of 30 data there are 0 unsuitable data (0\%) and 30 matching data (100\%). This shows that with the application of athlete determination, the trainer no longer makes manual data and can choose which endurance, physical, and tactical assessment categories to prioritize using application weighting factor.
\end{abstract}

Keywords : athlete, rock climbing, SAW, decision support systems 


\section{PENDAHULUAN}

Olahraga panjat tebing terbagi menjadi dua macam yakni panjat tebing yang dilakukan ditebing sesungguhnya dan panjat tebing yang dilakukan di dinding buatan. Sebagaimana yang diketahui, olahraga panjat tebing termasuk jenis kategori olahraga populer dikalangan remaja sekarang ini, terbukti dengan seringnya dilaksanakan kejuaraan panjat tebing baik skala nasional maupun interrnasional.

Pada olahraga panjat tebing, dipertandingkan tiga nomer pertandingan yaitu ketegori rintisan (lead), kategori kecepatan (speed) dan jalur pendek atau sering disebut dengan boulde.

Sebelum mengikuti sebuah ajang kompetisi, atlet akan menjalani program latihan yang dibuat oleh Pelatih dan koordinator Pembinaan dan Prestasi (Binpres) Federasi Panjat Tebing Indonesia (FPTI) untuk memaksimalkan kemampuan atlet sebelum mengikuti kejuaraan.

Berdasarkan masalah tersebut, maka diperlukan sistem penunjang keputusan yang dapat membantu Tim Pelatih dan Koordinator Pembinaan Prestasi (Binpres) Federasi Panjat Tebing Indonesia (FPTI) Kab. Tapin dalam memaksimalkan kemampuan fisik dan mental atlet agar mencapai target juara yang diharapkan. Metode yang digunakan dalam sistem penunjang keputusan pemilihan atlet panjat tebing terbaik ialah dengan Simple Additive Weighting (SAW). Metode ini menentukan nilai bobot untuk kriteria penilaian sampai dengan terpilih alternatif terbaik (Putri \& Hidayat, 2018). Pengambilan keputusan dilakukan dengan memberikan pertimbangan pemberian bobot atas empat kategori yaitu daya tahan, teknik, fisik, strategi.

\section{LANDASAN TEORI}

\section{A. Atlet}

Atlet (sering pula dieja sebagai atlit) adalah seseorang yang memiliki keahlian khusus dan kemampuan dalam olahraga atau bentuk lain dari latihan fisik. Menurut Kamus Besar Bahasa Indonesia, atlet adalah olahragawan, terutama yang mengikuti perlombaan atau pertandingan (kekuatan, ketangkasan, dan kecepatan).

\section{B. Metode SAW}

Metode SAW sering dikenal dengan istilah metode penjumlahan terbobot. Konsep dasar metode SAW (Simple Additive Weighting) adalah mencari penjumlahan terbobot dari rating kinerja pada setiap alternatif pada semua atribut (Fishburn, 1967), (MacCrimmon, 1968). Metode SAW dapat membantu dalam pengambilan keputusan suatu kasus, akan tetapi perhitungan dengan menggunakan metode SAW ini hanya yang menghasilkan nilai terbesar yang akan terpilih sebagai alternatif yang terbaik. Perhitungan akan sesuai dengan metode ini apabila alternatif yang terpilih memenuhi kriteria yang telah ditentukan.

\section{METODE PENELITIAN}

\section{A. Metode Pengumpulan Data}

a. Wawancara

Metode pengumpulan data dengan cara mengadakan tanya jawab yang dilakukan secara langsung kepada tim pelatih dan koordinator Pembinaan Prestasi (Binpres) Federasi Panjat Tebing Indonesia (FPTI) Kab. Tapin serta atlet panjat tebing tersebut.

b. Observasi

Pengumpulan data melalui pencatatan terhadap kategori dalam menentukan atlet panjat tebing sebagai objek penelitian. Observasi dilakukan pada setiap tempat pelatihan simulasi panjat tebing Kab. Tapin. 
Puspitasari, Kholdani, Arminarahmah - Sistem Penunjang Keputusan Pemilihan Atlet Panjat Tebing Menggunakan Metode Simple Additive Weighting

c. Studi Pustaka

Pengumpulan data dengan membaca serta mempelajari dokumen-dokumen, literatur, jurnal, dan buku-buku serta sumber lainnya yang berhubungan dengan Sistem Penunjang Keputusan Pemilihan Atlet Panjat Tebing Menggunakan Metode Simple Additive Weighting.

\section{B. Jenis Data}

Jenis data yang dipergunakan dalam pengumpulan data untuk penelitian ini antara lain :

a. Data Primer

Merupakan data yang diperoleh secara langsung dari opini, wawancara dan observasi berkaitan dengan Sistem Penunjang Keputusan Pemilihan Atlet Panjat Tebing Menggunakan Metode Simple Additive Weighting.

b. Data Sekunder

Merupakan data yang diperoleh dari sumber-sumber yang sudah ada misalkan buku, jurnal, laporan dan lainnya yang berkaitan dengan Sistem Penunjang Keputusan Pemilihan Atlet Panjat Tebing Menggunakan Metode Simple Additive Weighting.

\section{Metode Pengolahan Data}

Penelitian ini menggunakan metode Simple Additive Weighting (SAW) yaitu pengolahan data menggunakan pembobotan terhadap kriteria daya tahan, teknik, fisik, strategi para atlet panjat tebing. Berikut adalah variabel yang digunakan dalam penelitian ini :

Tabel 1 Variabel dan Bobot Menggunakan SAW

\begin{tabular}{|l|l|}
\hline Variabel & Bobot \\
\hline Sangat Rendah & 1 \\
\hline Rendah & 2 \\
\hline Sedang & 3 \\
\hline Baik & 4 \\
\hline Sangat Baik & 5 \\
\hline
\end{tabular}

Tabel 2 Kriteria Menggunakan SAW

\begin{tabular}{|l|c|c|c|c|}
\hline \multicolumn{1}{|c|}{ Alternatif } & C1 & C2 & C3 & C4 \\
\hline Atlet1 & 5 & 4 & 3 & 4 \\
\hline Atlet2 & 1 & 4 & 5 & 3 \\
\hline Atlet3 & 3 & 4 & 4 & 2 \\
\hline Atlet4 & 4 & 5 & 3 & 3 \\
\hline AtletN & 1 & 2 & 1 & 4 \\
\hline
\end{tabular}

Keterangan :

$\mathrm{C} 1=$ kriteria daya tahan.

$\mathrm{C} 2=$ kriteria teknik.

$\mathrm{C} 3=$ kritera fisik.

$\mathrm{C} 4=\mathrm{kriteria}$ taktik/strategi. 


\section{Rancangan Penelitian}

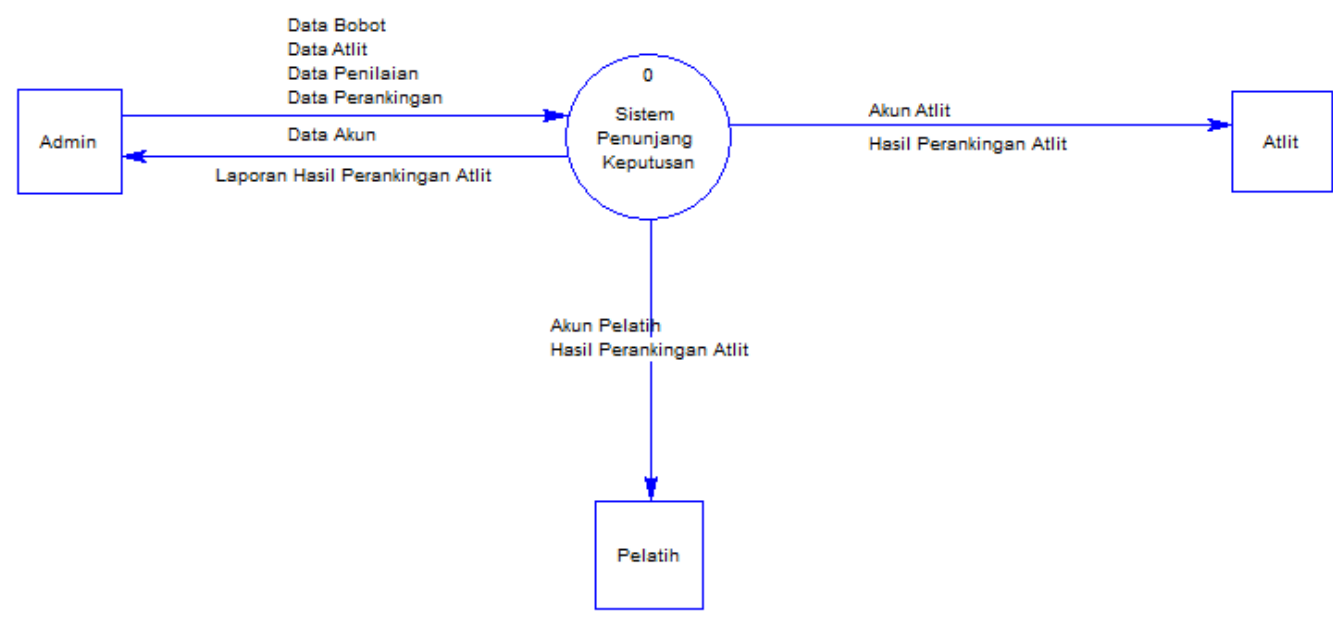

Gambar 1 Diagram Konteks

\section{E. Relasi Antar Tabel}

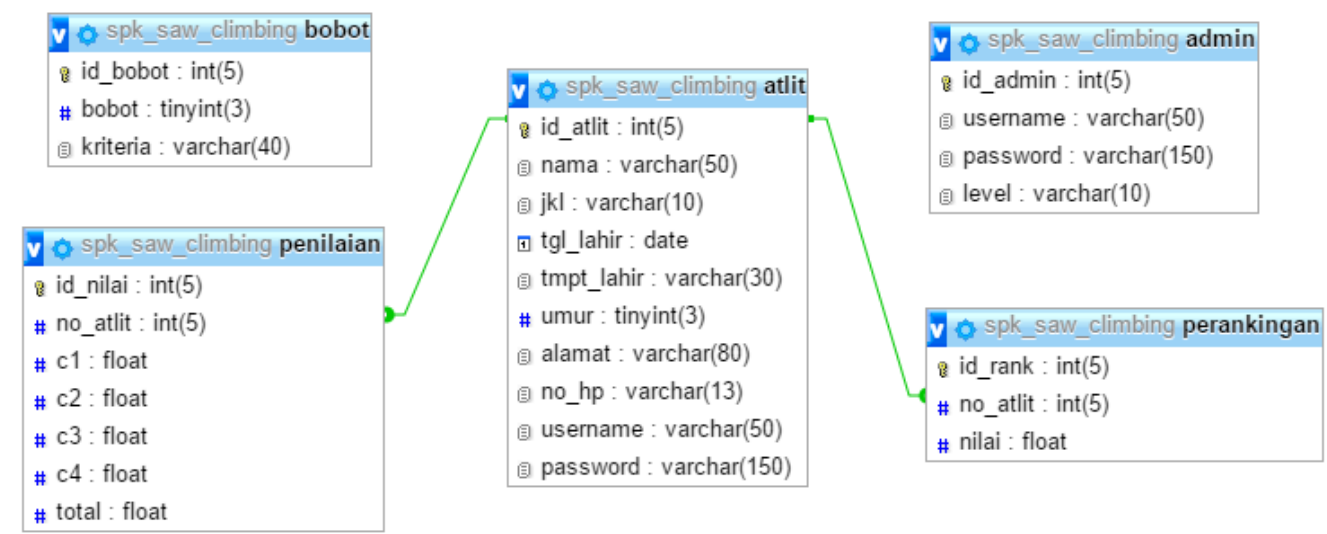

Gambar 2 Relasi Antar Tabel

\section{IMPLEMENTASI SISTEM}

\section{A. Hasil}

1. Form Login

Form login akan muncul pada saat pertama kali aplikasi dijalankan. Form login digunakan sebagai sistem keamanan user. Pada saat menuju ke halaman utama user wajib mengisi username dan password yang ada pada form login. 
Puspitasari, Kholdani, Arminarahmah - Sistem Penunjang Keputusan Pemilihan Atlet Panjat Tebing Menggunakan Metode Simple Additive Weighting

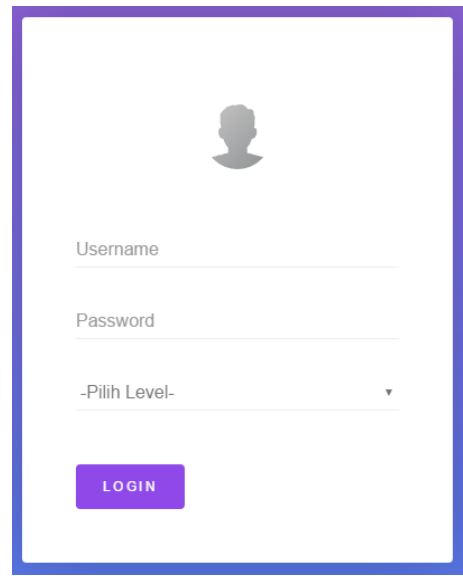

Gambar 3 Form Login

2. Halaman Utama

Terdapat beberapa menu dilaman sebelah kiri halaman utama ini :

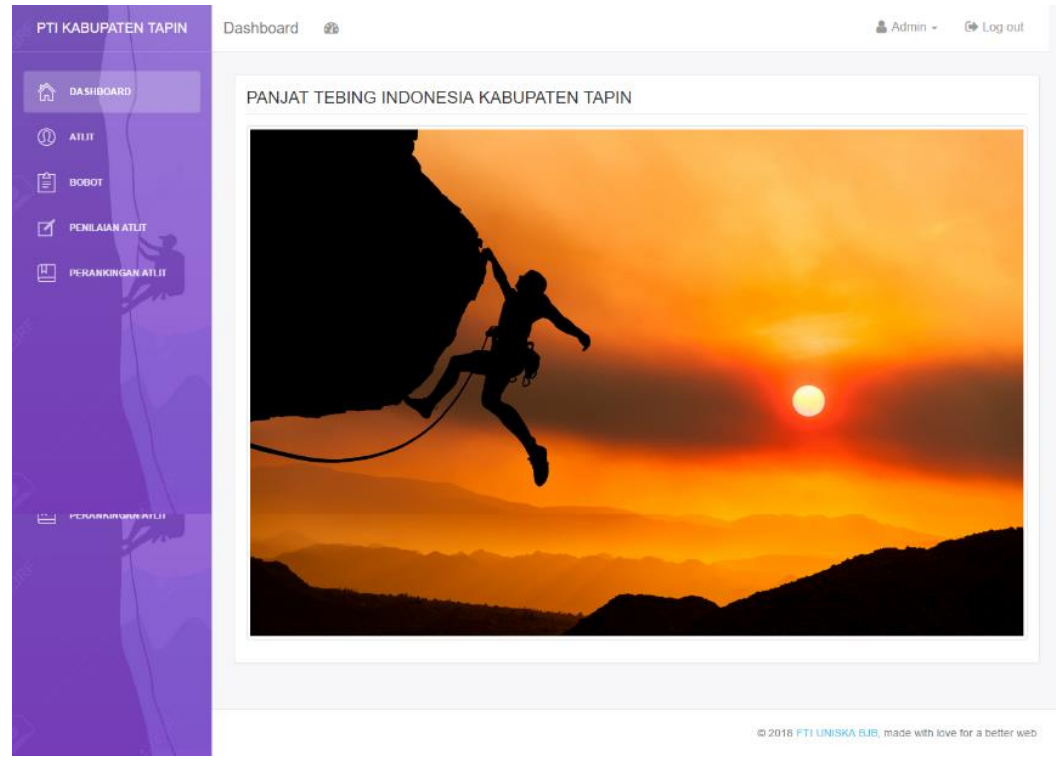

Gambar 4 Halaman Utama

3. Halaman Data Atlet

Halaman ini dirancang untuk mengolah data atlit yang berisi tabel dan form atlit. Form atlit terdiri dari nama, jenis kelamin, tempat lahir, tgl lahir, umur, alamat, no hp, dan username. 


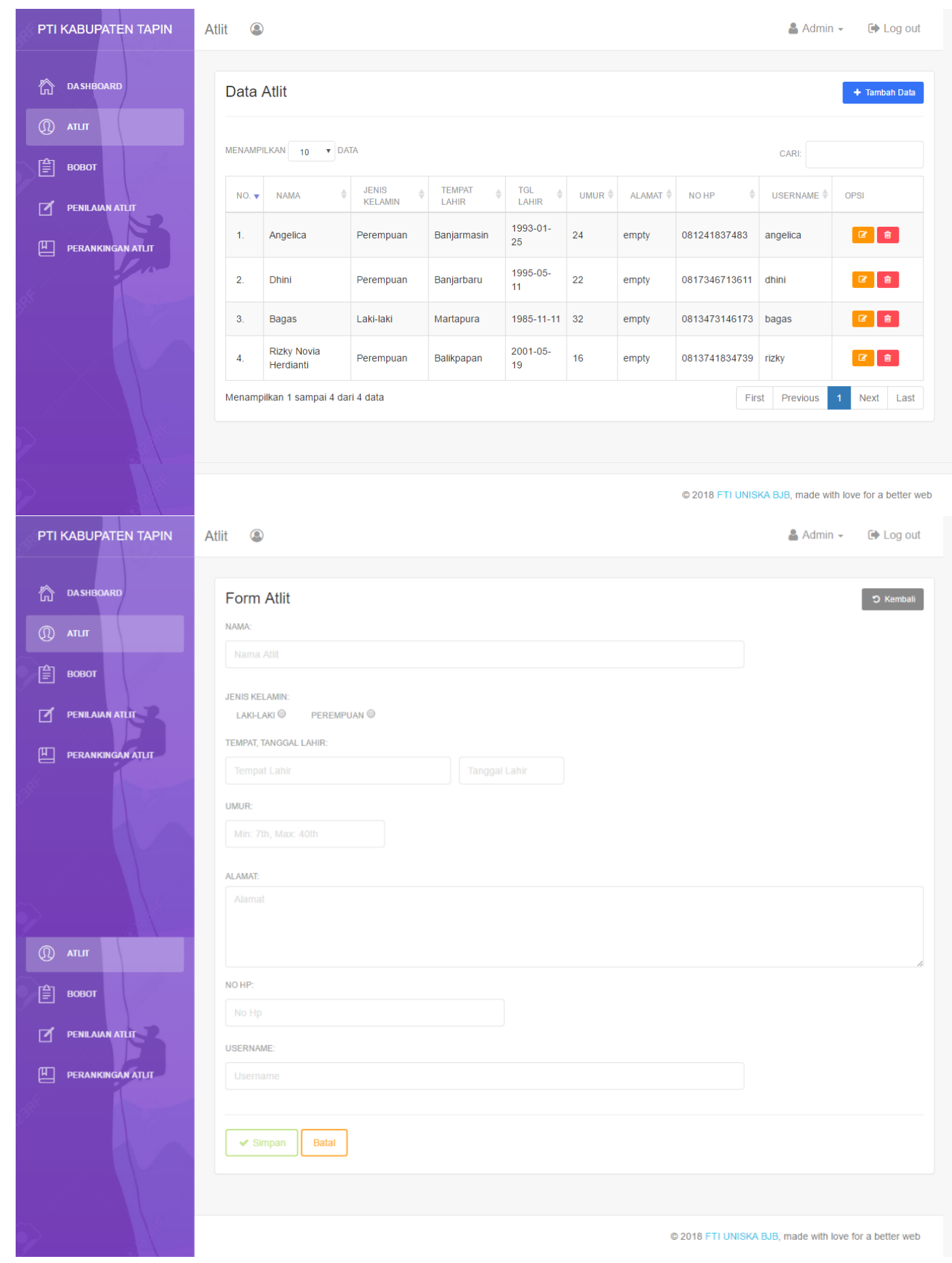

Gambar 5 Halaman Data Atlit

\section{Halaman Data Bobot}

Halaman ini dirancang untuk mengolah data bobot yang terdiri dari endurance, fisik, teknik, dan taktik. 
Puspitasari, Kholdani, Arminarahmah - Sistem Penunjang Keputusan Pemilihan Atlet Panjat Tebing Menggunakan Metode Simple Additive Weighting

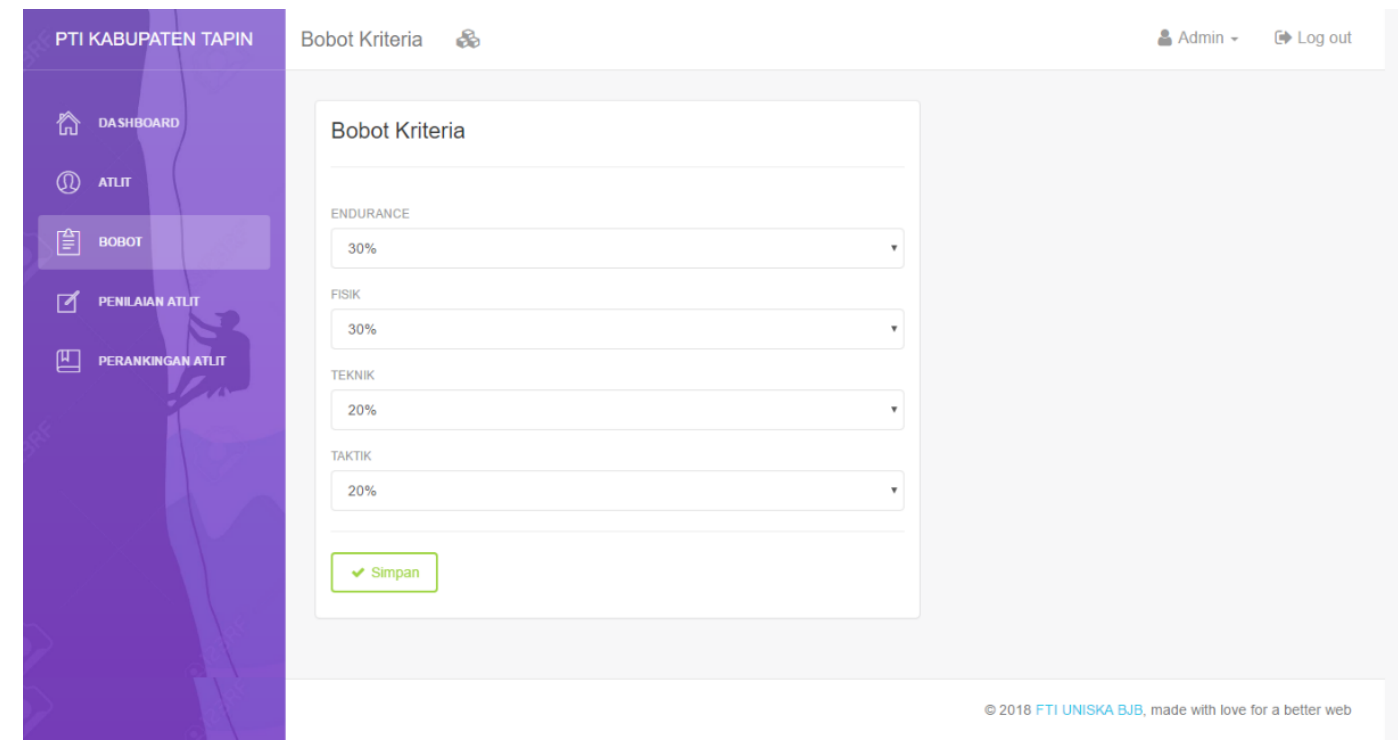

Gambar 6 Halaman Data Bobot

5. Halaman Data Penilaian Atlit

Halaman ini dirancang untuk mengolah data penilaian atlit yang berisi tabel dan form penilaian atlit. Form penilaian atlit terdiri dari nama atlit dan tabel penilaian atlit.

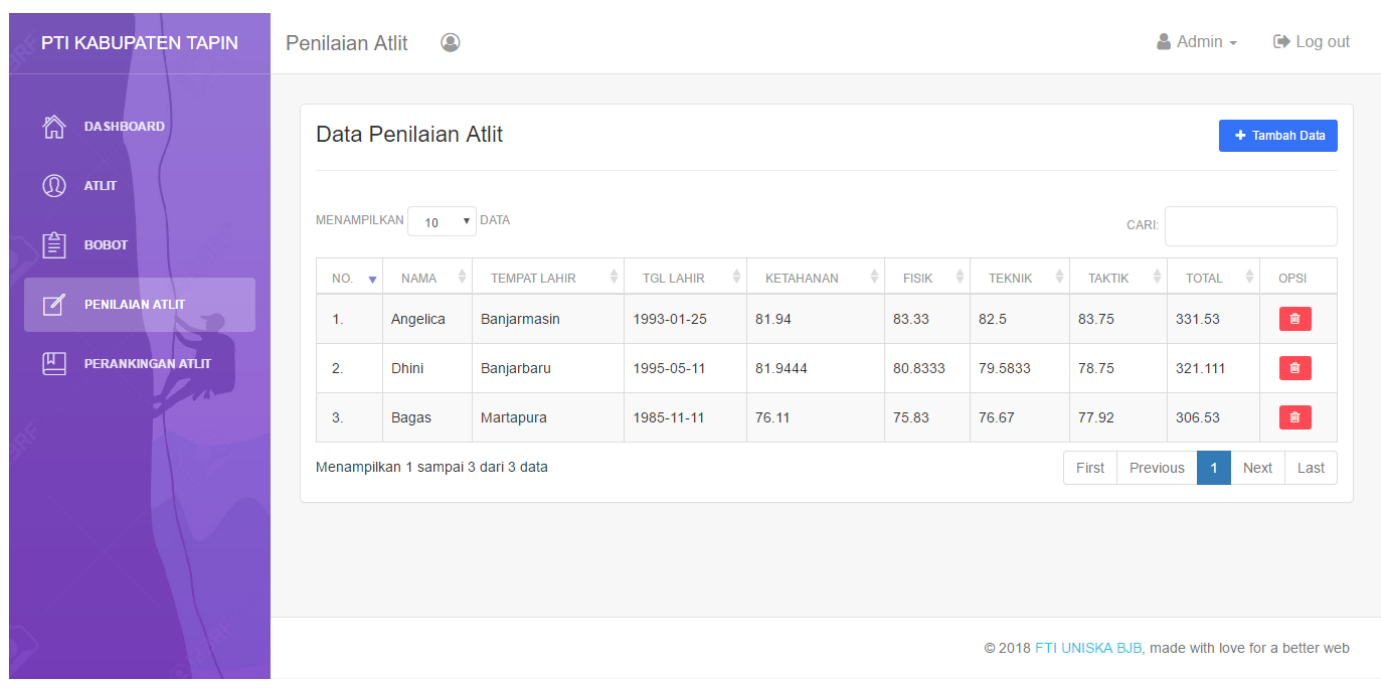




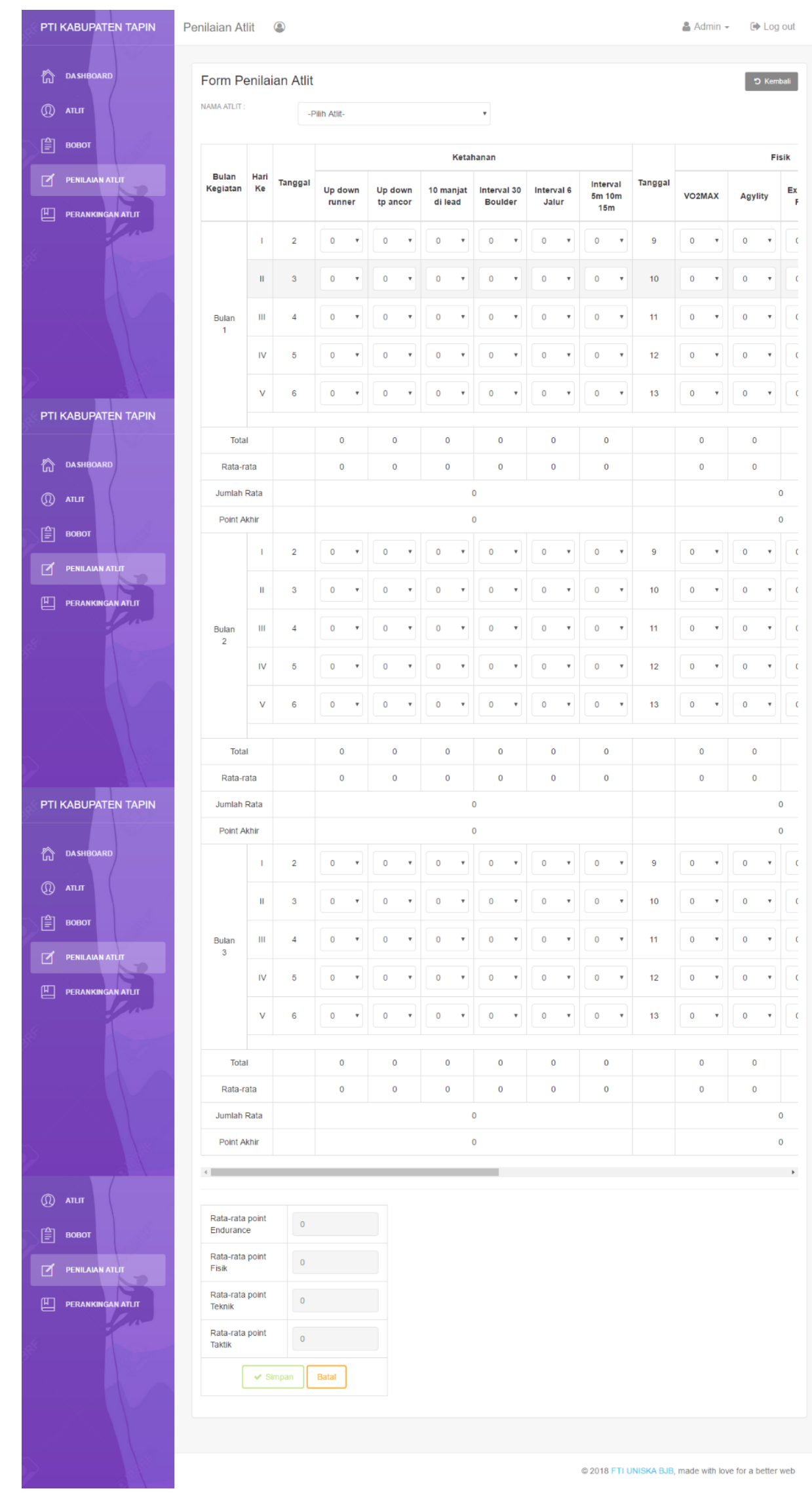

Gambar 7 Halaman Data Penilaian Atlit

\section{Halaman Perankingan Atlit}


Puspitasari, Kholdani, Arminarahmah - Sistem Penunjang Keputusan Pemilihan Atlet Panjat Tebing Menggunakan Metode Simple Additive Weighting

Halaman ini dirancang untuk menampilkan data hasil perankingan atlit menggunakan metode SAW

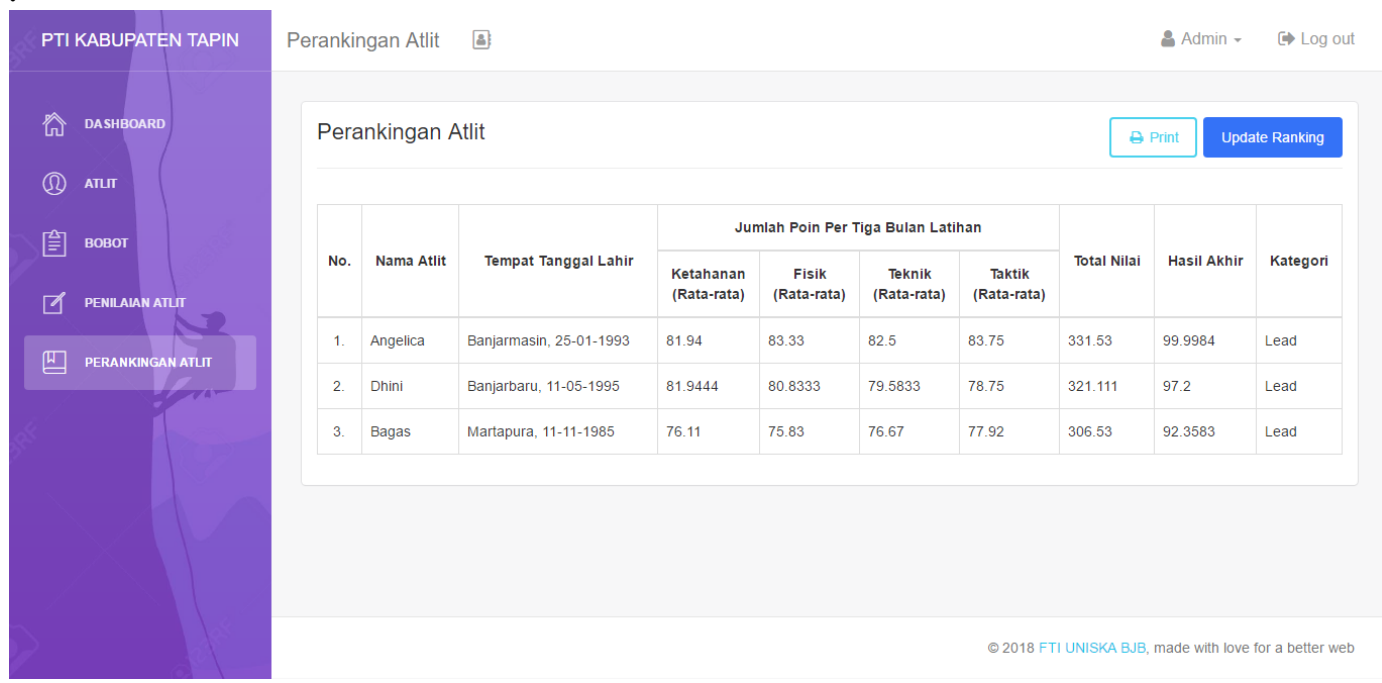

Gambar 8 Halaman Perankingan Atlit

7. Report Perankingan Atlit

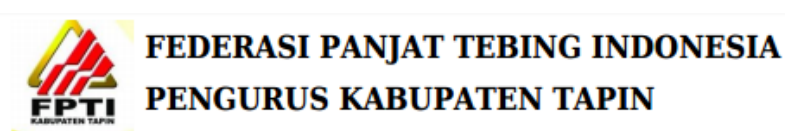

POIN PROGRAM LATIHAN ATLET PANJAT DINDING

\begin{tabular}{|c|c|c|c|c|c|c|c|c|c|}
\hline \multirow[b]{2}{*}{ No. } & \multirow[b]{2}{*}{$\begin{array}{l}\text { Nama } \\
\text { Atlit }\end{array}$} & \multirow[b]{2}{*}{$\begin{array}{c}\text { Tempat } \\
\text { Tanggal } \\
\text { Lahir }\end{array}$} & \multicolumn{4}{|c|}{ Jumlah Poin Per Tiga Bulan Latihan } & \multirow[b]{2}{*}{$\begin{array}{l}\text { Total } \\
\text { Nilai }\end{array}$} & \multirow[b]{2}{*}{$\begin{array}{l}\text { Hasil } \\
\text { Akhir }\end{array}$} & \multirow[b]{2}{*}{ Kategori } \\
\hline & & & $\begin{array}{l}\text { Ketahanan } \\
\text { (Rata-rata) }\end{array}$ & $\begin{array}{c}\text { Fisik } \\
\text { (Rata-rata) }\end{array}$ & $\begin{array}{c}\text { Teknik } \\
\text { (Rata-rata) }\end{array}$ & $\begin{array}{c}\text { Taktik } \\
\text { (Rata-rata) }\end{array}$ & & & \\
\hline 1. & Angelica & \begin{tabular}{|l|} 
Banjarmasin, \\
25-01-1993
\end{tabular} & 81.94 & 83.33 & 82.5 & 83.75 & 331.53 & 99.9984 & Lead \\
\hline 2. & Dhini & $\begin{array}{l}\text { Banjarbaru, } \\
\text { 11-05-1995 }\end{array}$ & 81.9444 & 80.8333 & 79.5833 & 78.75 & 321.111 & 97.2 & Lead \\
\hline 3. & Bagas & $\begin{array}{l}\text { Martapura, } \\
11-11-1985\end{array}$ & 76.11 & 75.83 & 76.67 & 77.92 & 306.53 & 92.3583 & Lead \\
\hline
\end{tabular}

Koordinator Pembinaan dan Prestasi

Federasi Panjat Tebing Indonesia (FPTI) Kabupaten Tapin

Muhklis, S. Kep.Ners

Gambar 9 Report Perankingan Atlit

\section{B. Hasil Uji Implementasi}

Pada uji implementasi sistem ini, proses yang dilakukan adalah membandingkan antara total nilai akhir secara manual (pretest) yaitu dengan menjumlahkan seluruh nilai - nilai dari indikator penilaian. Selanjutnya di bandingkan dengan total nilai akhir (postest) dengan menggunakan metode $S A W$ yang disebut dengan total Weighted Evaluation dari masingmasing data. Untuk melihat perbandingan hasil total Weighted Evaluation atlet panjat putra 
dan putri antara total nilai menggunkan sistem dengan menggunakan metotode Multi Factor Evaluation Process dapat di lihat pada tabel, di bawah ini :

Tabel 3 Perbandingan Pretest dan Posttest Atlet Panjat Tebing

\begin{tabular}{|c|c|c|c|c|c|c|}
\hline \multirow[b]{2}{*}{ No } & \multirow[b]{2}{*}{ Nama Atlet } & \multicolumn{2}{|r|}{ Pretest } & \multicolumn{2}{|r|}{ Postest } & \multirow[b]{2}{*}{ Keterangan } \\
\hline & & $\begin{array}{l}\text { Total } \\
\text { Nilai }\end{array}$ & Kategori & $\begin{array}{l}\text { Total } \\
\text { Nilai }\end{array}$ & Kategori & \\
\hline 1 & Zunaidi & 70,90 & Boulder & 70,71 & Boulder & Sesuai \\
\hline 2 & Rahmani & 71,74 & Boulder & 71,71 & Boulder & Sesuai \\
\hline 3 & Mukriyani & 80,21 & Lead & 80,04 & Lead & Sesuai \\
\hline 4 & Raidi Haitami & 69,90 & Speed & 69,71 & Speed & Sesuai \\
\hline 5 & Yayan Hidayat & 77,08 & Boulder & 76,77 & Boulder & Sesuai \\
\hline 6 & M. Firdan Ardika & 69,69 & Speed & 69,79 & Speed & Sesuai \\
\hline 7 & M. El Farezi Rezky & 81,39 & Lead & 81,50 & Lead & Sesuai \\
\hline 8 & M. Najmi Fadhilah & 84,51 & Lead & 84,58 & Lead & Sesuai \\
\hline 9 & M. Ustaza & 72,22 & Boulder & 72,29 & Boulder & Sesuai \\
\hline 10 & M. Ferza Fernanda & 67,85 & Speed & 67,92 & Speed & Sesuai \\
\hline 11 & M. Rezky Azhar & 67,50 & Speed & 67,50 & Speed & Sesuai \\
\hline 12 & M. Edward Anshari & 65,28 & Speed & 65,29 & Speed & Sesuai \\
\hline 13 & Miftahul Firdaus & 80,14 & Lead & 80,12 & Lead & Sesuai \\
\hline 14 & Syahreza Rayfanor & 66,88 & Speed & 66,88 & Speed & Sesuai \\
\hline 15 & Ahmad Hafie M & 63,68 & Speed & 63,75 & Speed & Sesuai \\
\hline 16 & Srie Retna sari & 82,88 & Lead & 82,83 & Lead & Sesuai \\
\hline 17 & $\begin{array}{l}\text { Rahma Wati } \\
\text { Maulida }\end{array}$ & 76,63 & Boulder & 76,50 & Boulder & Sesuai \\
\hline 18 & Galuh berlian M & 68,40 & Speed & 68,29 & Speed & Sesuai \\
\hline 19 & Aulia Devina & 67,40 & Speed & 67,38 & Speed & Sesuai \\
\hline 20 & Husnul Khatimah & 80,80 & Lead & 80,71 & Lead & Sesuai \\
\hline 21 & Khairunnisa & 81,04 & Lead & 80,92 & Lead & Sesuai \\
\hline 22 & Noor Azizah & 63,82 & Speed & 63,67 & Speed & Sesuai \\
\hline 23 & $\begin{array}{l}\text { Rabbiatul } \\
\text { Adawiyah }\end{array}$ & 80,28 & Lead & 80,50 & Lead & Sesuai \\
\hline 24 & Rukhmitha & 78,65 & Boulder & 78,62 & Boulder & Sesuai \\
\hline 25 & Sutra ani & 71,35 & Boulder & 71,50 & Boulder & Sesuai \\
\hline 26 & Rizky Fadhilah & 75,21 & Boulder & 75,25 & Boulder & Sesuai \\
\hline 27 & Trie Sumarmi & 74,62 & Boulder & 74,59 & Boulder & Sesuai \\
\hline 28 & $\begin{array}{l}\text { Zaidaufa Rizky } \\
\text { Utama }\end{array}$ & 64,13 & Speed & 64,13 & Speed & Sesuai \\
\hline 29 & $\begin{array}{l}\text { Rizky Novia } \\
\text { Herdianti }\end{array}$ & 69,51 & Speed & 69,46 & Speed & Sesuai \\
\hline 30 & $\begin{array}{l}\text { Ardha Kahnifah } \\
\text { Hidayat }\end{array}$ & 66,91 & Speed & 66,92 & Speed & Sesuai \\
\hline
\end{tabular}

Dari hasil postest di atas dapat mengetahui tingkat akurasi perhitungan menggunakan metode $S A W$ dengan menggunkan rumus:

$\frac{\text { jumlah data tidak sesuai }}{\text { jumlah total data }} \times 100$ dan $\frac{\text { jumlah data sesuai }}{\text { jumlah total data }} \times 100$ 
Puspitasari, Kholdani, Arminarahmah - Sistem Penunjang Keputusan Pemilihan Atlet Panjat Tebing Menggunakan Metode Simple Additive Weighting

jadi perhitungan akurasinya :

$$
\begin{gathered}
\text { data tidak sesuai }=\frac{0}{30} \times 100=0 \% \\
\text { data sesuai }=\frac{30}{30} \times 100=100 \%
\end{gathered}
$$

Setelah dilakukan perhitungan akurasi, maka didapat hasil perhitungan tingkat akurasi menggunkan metode $S A W$ untuk data sebesar $0 \%$ tidak sesuai dan $100 \%$ data sesuai.

\section{PENUTUP}

\section{A. Kesimpulan}

Berdasarkan hasil penelitian dan pembahasan yang telah dibuat dan dikemukakan, maka dapat diambil kesimpulan yaitu aplikasi penentuan atlet panjat dinding menggunakan metode $S A W$ yang dibangun dapat membantu pihak Federasi Panjat Tebing Indonesia (FPTI) di Kabupaten Tapin untuk melakukan pemberian penilaian yang sesuai dengan petunjuk penilaian. Hasil perhitungan aplikasi merupakan prioritas yang dibutuhkan sebagai pertimbangan oleh Pelatih dan Koordinator Pembinaan dan Prestasi (Binpres) untuk menentukan atlet sesuai dengan kategori. Hasil pengujian antara proses manual (pretest) dan menggunakan aplikasi (postest) menunjukkan untuk data awal dengan total data sebanyak 30 data terdapat 0 data yang tidak sesuai $(0 \%)$ dan 30 data yang sesuai (100\%). Aplikasi penentuan atlet panjat tebing ini membuat pelatih tidak lagi membuat data manual dan dapat memilih kategori penilaian ketahanan, fisik, teknik dan taktik yang mana yang ingin di prioritaskan menggunakan faktor bobot.

\section{B. Saran}

Sistem penunjang keputusan pemilihan atlet ini untuk kedepannya agar dapat dikembangkan lagi misalnya menggunakan dua metode gabungan, sehingga masih diperlukan pengembangan lagi menggunakan metode-metode yang lain atau penambahan variabel kriteria penilaian atlet untuk menghasilkan penelitian yang berbeda. Sistem penunjang keputusan pemilihan atlet ini masih berbasis web, ada baiknya bilamana ingin mengembangkan dapat dikembangkan lagi menjadi berbasis android.

\section{DAFTAR PUSTAKA}

Apendi, A. P. (2012). Kontribusi Kekuatan Otot Dan Flexibilitas Panggul Terhadap Hasil Panjat Dinding Kategori Rintisan ( Lead) Pada Cabang Olahraga Panjat Dinding. Universitas Pendidikan Indonesia.

Arifitama B. 2013. Penerapan Aplikasi DSS Seleksi Kandidat Atlit Boling Untuk Kejuaraan Dengan Metode AHP. Seminar Nasional Sistem Informasi Indonesia, Universitas Pembangunan Jaya, Banten. 2 - 4 Desember.

Bangkit R, Regasari R, Mahmudy W F. 2014. Sistem Pendukung Keputusan Pemilihan Atlet Yang Layak Masuk Tim Pencak Silat Dengan Metode Simple Additive Weighting (SAW), Prosiding. Universitas Brawijaya, Malang.

Birohumas. (2018). Tentang FPTI - Federasi Panjat Tebing Indonesia. Retrieved February 8, 2018, from http://www.fpti.or.id/tentang-fpti/

Harsiti, Saefudin, Rosalina V. 2014. Prototype Sistem Pendukung Keputusan Penyeleksian Atlet Berprestasi Dengan Menggunakan Metode Analytical Hierarchy Process (AHP). Prosiding SnaPP. Universitas Serang Raya, Banten.

Kusumo T, Widyatmoko K. 2015. Sistem Pendukung Keputusan Seleksi Atlet Basket Pada PPLPD Jateng. Prosiding. Universitas Dianuswantoro, Semarang. 
Putri, L. S., \& Hidayat, N. (2018). Sistem Pendukung Keputusan Pemilihan Mitra Jasa Pengiriman Barang menggunakan Metode Simple Additive Weighting ( SAW ) Technique for Other Reference by Similarity to Ideal Solution ( TOPSIS ) di Kota Malang, 2(3), 1219-1226.

Setyawan A, Sutariyani. 2013. Sistem Pendukung Keputusan Seleksi Calon Atlit Bulu Tangkis Berbakat PB. Djarum Kudus. Jurnal Ilmiah Go Infotech, STMIK AUB, Surakarta. Volume 19 No. 1.

Utomo S.P.K, Kurniawan P. 2016. Sistem Penunjang Keputusan Dalam Pemilihan Pemain Untuk Posisi Tertentu Pada Sepak Bola. Seminar Nasional Teknologi Informasi dan Multimedia, STMIK AMIKOM, Yogyakarta. 6-7 Februari. 